\title{
Strategic scenarios of global logistics: what lies ahead for Europe?
}

\author{
Marco Mazzarino
}

Received: 9 October 2010 / Accepted: 18 December 2011 / Published online: 8 January 2012

(C) The Author(s) 2012. This article is published with open access at SpringerLink.com

\begin{abstract}
Introduction The current global crisis and other socio-economic and political events highlight the need for a better understanding of future (medium/long term) developments in transport and logistics systems and networks worldwide in a context of sustainability. Quite surprisingly, although transport and logistics are rather relevant sectors in global growth and trade, literature on future scenarios of logistics systems, identifying potential agents of change and forecasting new trends in global patterns of medium/long term logistics flows, turns out to be quite limited. While purely quantitative forecasts of logistics parameters and variables are easily available from a variety of sources, we found that studies using qualitative and strategic approaches in the building of future scenarios are mostly developed for sectors other than logistics and transportation (e.g., manufacturing). Therefore there is the need to address the issue of scenariobuilding in the field of global logistics through an efficient strategic method. Although few studies (the most relevant being Lapide's MIT SC2020 Project: Supply Chains Futures) have thus far adopted it, the Strategic Planning Approach (SPA) provides just such methodology.

Methods The paper seeks to fill this gap by employing a quali-quantitative methodology based on the SPA to provide a number of macro medium term scenarios in the field of global logistics and assessing the impacts on the European area. Following a comprehensive literature review, a
\end{abstract}

M. Mazzarino

Università IUAV di Venezia - Transport Research Laboratory,

Ca'Tron, Santa Croce 1957,

30135 Venezia, Italy

M. Mazzarino $(\triangle)$

Puglie Di Domio 143. 34018 San Dorligo della Valle,

Trieste, Italy

e-mail: mazzarin@iuav.it preliminary grid of main drivers of change is derived to be presented for focus groups analyses. The groups are representative of both supply and demand perspectives within the global logistics sector.

Results The analyses are conducted in a semi-structured interviews format where a number of strategic scenarios for global logistics are built - each scenario defined in terms of a combination of strategic drivers. In particular, results show how a specific model at the macro level - Symmetric Global Logistics Model (SGLM) - will be likely to prevail on a global scale, in which two fundamental sub-components (local/global) will play a determinant role. The impact of the SGLM is then strategically assessed with regards to European logistics systems.

Conclusion In conclusion, Europe is likely to face a strengthening of both its logistics and industrial capabilities - though at a different pace of development with respect to emerging economies - in a context in which North African and Eastern European markets will play a fundamental role in productionlogistics platforms.

Keywords Global logistics · Logistics networks ·

Scenario-building $\cdot$ Network design

\section{Introduction}

The aim of the paper is to provide a number of probable future scenarios concerning the development of logistics networks (procurement, production and distribution) on a global level in the medium/long term by using a qualitative and strategic approach, and assess the strategic impacts on the EU area. In other words, we try to envision how logistics networks will look like in the future. Scenario-building is an indispensable tool for policy-makers as it seeks to create reliable guidelines to facilitate the most productive courses 
of action. The following scenarios are intended as illustrations of potential future patterns in logistics flows among major global regions (logistics platforms).

In our research, quite surprisingly, even though transport and logistics are rather relevant sectors in global growth and trade, literature on future scenarios of logistics systems, identifying potential agents of change and forecasting new trends in global patterns of medium/long term logistics flows, turns out to be quite limited. Specifically, there is an incredible lack of studies employing a qualitative and strategic approach to these issues. While purely quantitative forecasts of logistics parameters and variables are easily available from a variety of sources, we found that studies using qualitative and strategic approaches building future scenarios are mostly developed for sectors other than logistics and transportation (e.g., manufacturing) [41].

Additionally, in building a reliable scenario of global logistics, it is essential to address the issue concerning the employment of a functional strategic method. Current working methods must be complemented by a more strategic vision of the future based on qualitative approaches such as the Scenario Planning Approach (SPA). Since few studies employ the SPA methodology to address the issue (the most relevant being [26]), this paper tries to fill the gap by employing a quali-quantitative methodology based on the SPA. We decided to overlook approaches commonly found, for instance, in regional economic theory as SPA methods are known to produce a robust view of the future [29]. SPA $[7,41]$ involves some visionary and provocative perspectives compared to conventional approaches, giving some new insights on scenario-building for global logistics. The key differentiator of the SPA is an acknowledgement of the future's margin of variability, as suggested by an overlapping and often conflicting array of available forecasts. The details of the approach are laid out in steps and they deal with both quantitative and qualitative aspects in logistics networks' future developments.

The paper is organized as follows. We begin with a presentation of a literature review on the issue of SPA as applied to the logistics sector. Subsequently, the SPA methodology is introduced in detail and its application discussed. In the methodology, the first procedural step consists of identifying a number of macro-factorial-key driverstrends and challenges determining changes that in the medium/long term can be deemed significant to the design of global logistics systems and networks. Secondly, key drivers are combined to construct one or more scenarios. More rigorously, a scenario can be defined in terms of a probable combination of some or all the drivers [2936].

An analysis of the literature is performed to largely address the first procedural step-identification of a grid of key drivers-while the scenario-building process - the combination of major drivers - is developed through what in the Scenario
Planning literature is termed brainstorming - a series of semistructured interviews and focus groups comprised of some 6 to 10 representatives from major logistics players.

Key drivers' analyses and discussions are performed to produce a number of scenarios from which to draw conclusions and assess some strategic impacts on European logistics.

\section{Literature review}

One of the few relevant studies employing SPA methodology to the future of logistics networks (in particular, supply chains), $[25,26,43,45,46,47,48]$ aims at a definition of excellence within the field of logistics/supply chain. It first identifies critical current and historical factors determining the success of a logistics/supply chain. The identification of some drivers of change and their possible impacts on logistics networks subsequently allow these excellence models to be projected into the future.

Figure 1 summarizes the MIT study [26]:

Although experts and researchers commonly rely on historical data to develop a singular view of the future, [42] underlines how when predicting the future uncertainty plays a major role. In this sense, forecasts essentially replicate history and have a limited view of what is plausible in the future. Instead, the future is open to multiple interpretations and is not anchored solely to the precedents of the realized past. [43], by referring to the MIT study SC2020, highlights the relevance of Scenario Planning to predict future supply chains (Fig. 2).

A Scenario is defined as a self-consistent story of possible future world derived by a host of macroeconomic factors and relevant government actions [46]. When using scenario planning, actors need not predict the exact future, rather the scenarios provide forethought on the range of possible

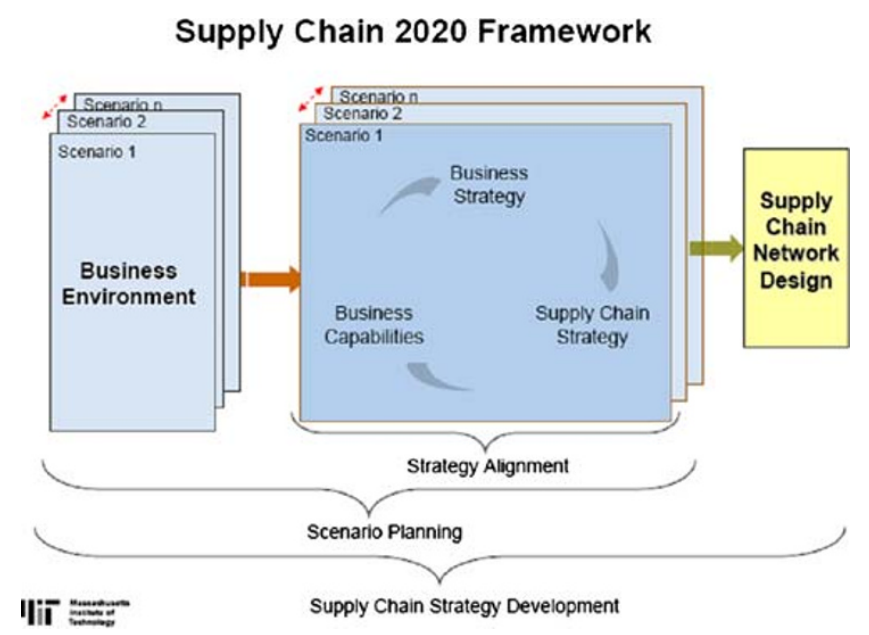

Fig. 1 The Supply Chain 2020 Framework. Source: [26] 


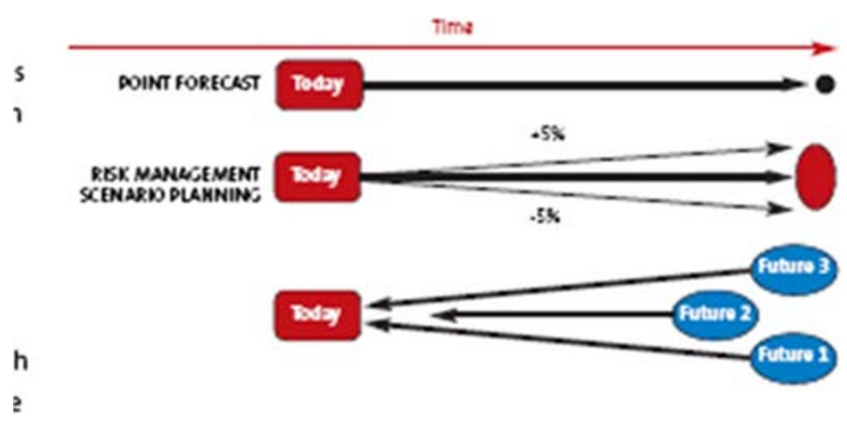

Fig. 2 A different approach for the exploration of the future. Source: [43]

relevant contingencies- "forethought, but not forecasting" [46].

It is also well known [47] that forecasts and predictions about the future have little chance of realization regardless of the methodology or model used - especially where very long term forecasting is involved. In [47], the Scenario Planning Approach, where the future's uncertainty is taken into account, is recommended. Moreover, the literature review shows that there is a tremendous lack of published structured studies that look at the future of supply/logistics chains using this approach [46]. Therefore, we try to fill this gap, in particular by addressing the following research questions [45]:

- what will supply/logistics chains look like in the mediumlong term (say, 2020)?

- What macro factors will impact them?

It is noted [47] that most of the literature supports the vision of a highly connected world in which supply and logistics chains will be extremely fluid. In this vision, activities throughout the chains linkage are triggered by signals from end customers, supported by systems that will run efficiently, and facilitated by innovative production, communication, and information technologies. Furthermore, companies will share information freely and co-create products for the end customer. However, as it is generally agreed [47] that the future will not be so perfect, the best approach to forecasting is an SPA [47] based on a holistic analysis of macro factors. In our study, we follow this view.

The MIT study [48] provides relevant information on the identification and classification of probable drivers of change for the future of logistics and supply chains. However, we note that scenarios are derived without specifying the impacts on the logistics networks and supply chain design - our paper's objective. In other words, the study's scenarios are generally conceived as general states-of-theworld; but while these are useful to logistics decisionmakers, they have no relevance on the final configuration of global logistics networks, whether quantitative or qualitative features. While no likely impact on the configuration of logistics structures is given, final scenarios (Synchronicity, Alien Nation, and the Spin City) are defined merely in order to enable managers and decision-makers to act in line with specific environments (states of the world). In our study, the results provided assess the most likely structure of future logistics networks and design (which is missing in the MIT study) as a function of various strategic drivers, thus supporting strategic decisions by companies and public bodies.

Clearly, the logistics and supply chains processes are a product of complex interactions between macro factors and the capabilities of organizations. Thus, the future of logistics chains is inherently interwoven with the future state of macro factors. Interestingly, in the literature [47] most of the studies fall into two categories, namely:

- macro factors: the likely drivers of future changes-generally beyond the control of a single organization - without any explicit connection with the future configuration of logistics chains;

- supply/logistics chain vision: the strategic or operational shifts in manufacturing systems-general business practices - without explicitly identifying the underlying drivers of future change.

In our paper we try to bridge the gap between these two categories. We focus on the analyses (mostly through desk research) of macro drivers that are likely to influence the logistics chains and through focus groups' discussions link such analyses to the expected impacts on logistics chains. Finally, we give our interpretation of the different views regarding the impact of macro factors on the logistics chain design [47].

Similar techniques are employed in [13] where four different scenarios for the European transport and logistics sector are built, where each scenario provides plausible hypotheses about the future. A scenario is defined as a coherent description of possible outcomes of a number of drivers that may influence and change the shape of the system over a given period of time. Scenario analyses and exercises do not presume to predict the future but rather provide a description of possible future outcomes. Scenariobuilding is designed as a two-stage process [13]:

- first, the main macro drivers of change are examined. Once these drivers and dimensions are identified, they are "fleshed out" into plausible and concrete scenarios;

- second, the potential implications inherent in different configurations of macro drivers are examined. This investigation is carried out partly through desk research and partly by drawing on strategic discussions between experts and company managers.

Some other studies [18] try to build upon an integrated architecture of parameters in order to assess the impact on the design of supply and logistics chains.

In the field of regional economics the issue of future trends in logistics networks is indicated as an open question 
to the research agenda. [49] proposes a research agenda addressing the question of the future of global logistics structures and related challenges. As emphasized in our paper, this study of the reactions in logistics structures should not be intended merely in terms of changes in transport costs, but also in terms of changes in strategic key drivers on a global level. Our paper focuses on the identification of strategic drivers of various nature capable of producing relevant impacts on global logistics structures, and therefore well beyond the confines of specific logistics and transportation aspects (e.g., service level, product individualization, etc.), as is commonly found in regional economics and logistics management literature [14].

Like [49], our paper gives a contribution to improve the understanding of global logistics networks re-design processes and relative impacts on the economy. But where [49] focuses on developing better quantitative models and integrating logistics modeling in the spatial CGE, we focus on the improvement of qualitative and strategic techniques.

Lakshamanan and Anderson [24] focus on the impact of transport and logistics systems on economic growth. They first specify the link among transport systems and regional growth in aggregate terms. They also discuss a microeconomic approach in which the benefits produced by improved transport systems are analyzed at a firm-level. Finally, they put the analysis in a CGE context. Overall, the main driver producing positive impacts on economic growth is considered to be an improvement in transport investments.

FREIGHTVISION [15] tries to envision how European Freight Transport will be in 2050. It is a policy-oriented study focusing mainly on the policy actions needed to make the European transport system more sustainable, in particular by fixing given targets in various sectors (pollution, congestion, etc.). Moreover, from a scenario-building point of view, the project is based on reproducing current (mainly quantitative) trends into the future, without considering a number of strategic factors of change.

HOP! Macro-economic impact of high oil price in Europe. Project funded by European Commission-DG Research6th RTD Programme [20] provides for some estimated impacts on the European economy, including transport, due to a prolonged increase in energy prices. It uses the POLES and the ASTRA models in an integrated way to simulate a number of future scenarios and the expected direct and indirect impacts due to energy prices increase at a European level. Scenarios are basically built on the basis of a what-if logic, by making some assumptions on key variables. Clearly, even though these are traditional methods for scenario-building, they do not explain the why's and how's of key variables' behavior over the given period.

Some other studies [3] address the issue of improving logistics performance at spatial level, as a competitive network of global logistics is considered to be the backbone of international trade. In particular, they suggest the use of the LPI (Logistics Performance Index) in order to compare various world regions from a logistics performance point of view and to identify, especially in developing countries, logistics bottlenecks while facilitating international trade and transportation.

\section{Methodology}

It is well known that one of the most relevant elements of competitiveness at different levels - from micro (single-firm) to meta (e.g., cluster and districts) and macro (entire regions) consists of the capability of making reliable forecasts and measuring their impact on the performances of the organizations involved.

The Strategic Planning Approach represents an effective tool for a strategic study on global logistics. The goal of SPA $[19,39,40]$ is not to illustrate the exact future as much as it is to make actors aware of probable states of the world and strategically identify the impacts on various systems. Given that these methods are widely used in a variety of industries, their use in the logistics sector (procurement, production and distribution), which along with transportation represent a significant strategic industrial factor for global growth and trade, is surprisingly limited. On the other hand, various sources merely provide us with a number of quantitative forecasts on logistics and transportation variables.

An SPA approach was firstly employed in a seminal study by Shell Corporation as a powerful DSS (Decision Support System) to face highly uncertain scenarios related to the oil crises of $1973[54,41]$. When aiming at "imagining the future", each forecasting technique turns out to have its own advantages and limitations.

Compared with other forecasting techniques (e.g., contingency planning, sensitivity analysis, etc.), SPA shows some advantages in that:

- it considers combinations of uncertain events, not single uncertainties;

- it addresses significant interactions among all major variables, not just a few;

- it is less formalized and more flexible.

However, important limitations to be acknowledged are:

- the methods are mainly born from practice;

- the methods have a quite subjective and heuristic nature.

As we can see, SPA methods are particularly useful when dealing with qualitative aspects that could be hardly addressed by mere quantitative techniques. Furthermore, SPA methods are recommended in application to long term 
forecasts and broad spatial dimension where uncertainty plays a major role. In short, SPA methods are suitable to highly uncertain and complex forecasts - a most typical aspect in forecasting global logistics networks.

SPA methodology develops through the following logical steps. The first two steps are mainly developed on the basis of a literature review and are concerned with:

- the identification of a number (grid) of key drivers of change in the field of global logistics;

- the definition of logical relationships among drivers for the establishment of a coherent framework of reference.

Subsequent steps are implement through focus group sessions (technically, brainstorming) held among leading companies' representatives chosen with respects to both supply and demand perspectives of the global logistics sector. Such steps are concerned with:

- discussion on the individual impacts on future logistics networks of each driver;

- preliminary scenario-building results (e.g., combining drivers)

- final definition of major global logistics scenarios based on common views, share visions and general agreement.

We build a supply panel-comprised of various types of logistics operators (integrators, transporters, port operators, etc.) - and a demand panel comprised of leading experts and shippers representing industrial and retailing companies. Overall, we involved some 15 representatives, averagely two representatives from each logistics chain in three rounds of discussion. On the basis of the grid of key drivers presented to them as a result of the first two steps, both panels are then asked to discuss future scenarios.

The panels takes into account the specifics of logistics/ supply chains in both manufacturing and retailing perspectives, including: "white", automotive, aluminum, consumer electronics, textile and clothing, fashion and eyewear, luxury.

Clearly, the selection of the above logistics chains is arbitrary and partial. However, they refer to relevant economic sectors for the European economy. The structure of the panels is in line with a typical brainstorming process within the SPA. Moreover, representatives in the focus group also provided expertise insight into future logistics trends often beyond their industry. Our paper's results mainly represent aspects on a general agreement among these experts, and therefore across industries, on the future of logistics networks.

\section{Identification and discussion analysis of key drivers}

The comprehensive literature review is conducted to derive a preliminary grid of drivers to be presented for focus groups' discussion in order to identify a clustering of main drivers of change capable of significantly influencing geoeconomical scenarios [55] in the field of logistics at a global level $[13,18,26]$. It is important to note that we mainly focus on macro drivers that are not directly under the control of the logistics actors, e.g., internal to the logistics systems [47]. In fact, it is in this field that a relevant gap in the literature is found.

Focus groups are developed at this stage in order to conduct a mainly qualitative analysis and discussion of each driver's individual impact in the overall scenario-building process, and assess preliminary logical relationships among individual drivers.

Identification, classification and analysis of key drivers [11] should not be viewed as a generic exercise concerning the shaping of overall global patterns, but must be strictly applied to the logistics field - the chief purpose of our study. In our study, results are focused on highlighting a functional relationship between key drivers and logistics scenarios to allow interpretation of the drivers' influence on the design of a global logistics network. From the analysis of drivers one should be able to identify specifically:

- the most relevant macro-regions/systems at spatial level (macro logistics nodes/platforms and markets), and their main characteristics, especially in terms of relative importance (weights);

- the most relevant flows, and their characteristics, among such macro-nodes.

Each scenario then describes a state-of-the-world in the logistics field, which is given by a specific pattern of flows among different macro-regions (logistics platforms) at global level.

As a result, we can present the following list of key drivers:

a) ecological drivers:

- energy costs;

- overall scarcity and distribution of natural resources;

b) economical drivers:

- emerging markets;

- balance of global economic power;

- trading blocks;

- financial and economic crisis;

c) technological drivers;

d) demographic drivers:

- aging population in developed countries;

- growth of global population;

e) regulatory drivers and sustainability.

In the next sub-paragraphs we present the analysis of each driver. 
4.1 Ecological drivers: the cost of energy and the issue of scarcity and distribution of natural resources

It is generally predicted a production-peak for fossil resources in non-OPEC countries in 2020, followed by a peak in OPEC countries soon after. The cost of a barrel in that period would range between $\$ 200$ and $\$ 400$.

These events raise some strategic questions in the field of logistics [44]:

- will locating production platforms to off-shoring countries still be the right thing to do economically? How should global logistics networks be re-designed? Would it be convenient to re-locate production platforms closer to home ${ }^{1}[10]$ ?

- will companies have to rethink its logistics network design based on a long term sustainability model?

The cost of energy clearly represents one of the main drivers, since it can heavily influence the design of logistics networks. Some of the results presented in this paragraph are among the most important ones in the overall analysis, and they will be included in the general conclusions. Our focus groups found that, due to an increase of energy costs, a clear tendency toward shorter logistics chains around the world would likely emerge within both procurement and distribution logistics systems [46]. For this reason, energy is the most significant factor in the shortening of logistics chains and the resulting closer-to-home trend. Due to the energy driver's trend toward higher costs, logistics and production platforms must be strategically relocated. But on a more tactical level, factors such as the availability of labor, capital, and above all supply chain actors should also be considered. In other words, one of the most significant constraints in the re-designing of a closer-to-home logistics network consists of the availability of hard equipment (infrastructures, machineries, etc.) and of a good network of logistics chain actors, especially suppliers. For instance, many participants of the focus groups emphasize that the difficulty in moving production and logistics platforms to China is due not so much to the need of finding employers, but to the burden of establishing completely new production and logistics networks and relationships, especially with suppliers.

We can generalize the issue by asking: if rising energy costs encourage a relocation of production sources, where will that relocation be? In other terms: one "comes back

\footnotetext{
${ }^{1}$ These are, for example, some results coming out from a recent analysis involving about 150 CEO's of logistics companies worldwide. From this survey, a significant trend to move logistics platforms away from Asia and back to the US is identified (11 on 20 CEOs). At the same time, $20 \%$ of CEO's of European logistics companies is moving logistics platforms to Eastern Europe [10]
}

home", but "where is the market demand"? From our analysis and focus groups some clear results come up: logistics chains will shorten and main sourcing points will be (re) located near the market ("we will produce where we find a market demand"). Major markets - we will touch upon the issue later on-will be those of the BRICS (and prospectively of MIK) ${ }^{2}$ countries, while North America and especially Europe will show less relevant growth rates.

In short, there will be a more local on local model of economic and logistics development.

Energy sources are clearly a relevant driver determining future global logistics scenarios. However, the role of other (strategic) natural resources-in terms of their availability and (spatial) distribution-matters as well, including that of rare materials and water. Indeed, some experts in our focus groups often pointed out that water will be among the most important factors of future logistics scenarios. Many production and logistics processes are based on water consumption, thus a reduction of its availability is certainly capable of producing a relevant impact on them. Companies have then a strong incentive to make its use more efficient and to lay down strategies to control strategic sources. ${ }^{3}$

To the extent to which - as we will see-forecasts on global GDP would predict a probable global increase and an eastward shift in economic power [53], a clear tendency toward a global competition on strategic natural resources emerges. Scarcity will have inflationary effects on commodity prices. Note for instance [4] the impressive strategy carried out by China relative to the control of strategic resources in Africa needed to guarantee its economic development. From a transportation and logistics point of view, the analysis of flow patterns between China and Africa represents a very interesting issue to be studied. As of recently, China has been carrying out an effective strategy to control strategic natural resources in Africa, which is based almost exclusively on bilateral agreements including trade, direct investments, infrastructure provision and loans. Therefore, on top of scenarios characterized by a more localized model of development, one should also consider the development of various strategies - and their impacts on logistics-aimed at controlling input resources for production and consumption activities.

The issue of resource availability can be referred to the human ones $[8,32]$ as well: where will the most significant innovation processes take place? Consider that:

- China and India will "produce" more and more engineers and college-educated students;

\footnotetext{
${ }^{2}$ Mexico, Indonesia, Korea

${ }^{3}$ For instance, out of the overall costs of environmental footprint in the "white" sector, some $85 \%$ is due to water consumption at home, while $3 \%$ is due to logistics activities only ...
} 
- interconnectivity enabled by new technologies will not force Eastern people to move toward Western countries;

- systems of intellectual property rights are different in Eastern countries.

Some provocative results from our analysis relate to the possibility for some regions - e.g., Europe ${ }^{4}$ - to become like China today. In fact, for European countries the following economic scenario could be illustrated:

- a relative role as consumer market, due to the stagnation of per capita income and a rate of development lower than that of other world economies;

- under-developed logistics systems (tendencies to move away industrial locations would also result in a downgrading of logistics - move/store - structures and systems supporting production and distribution activities);

- ceaseless migration flows from non EU Southern countries.

As a matter of fact, these characteristics resemble those of the initial steps of economic development in China where notwithstanding a huge availability of workers the consumption markets and logistics systems remained relatively limited.

However, a trend toward shorter logistics chains and a large availability of workforce would mean for Europe, especially its Southern regions [30], a formidable driver of potential industrial and logistics development. We could therefore envision a European scenario where the currently strong market for final consumption would be coupled with a significant expansion of industrial and logistics activities.

As for the quality of human resources related to the innovation issue we underline how Europe, traditionally featuring high ratios of educated citizens, could again play a significant role, with such potential increasing significantly when we include Eastern Europe. Europe will thus play an important role also in terms of innovation processes.

\subsection{Economic drivers: the role of emerging markets}

From both a procurement and distribution logistics point of view, which geo-economical regions will be the future's most important? One of the preliminary issues to be addressed is the role of China, since China seems to feature prominently in the scenario planning minds of many companies [46]. What will be its role in the future? Some of the discussion topics included within what our focus groups came to identify as the "China question" emerging from the literature addressed are [46]:

- low-cost producer vs. high-cost consumer market;

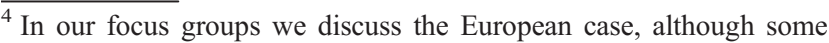
results can be valid for other world regions as well.
}

- new global power (virtually independent) vs. probable risks of implosion and political instability (class conflict, etc.).

We note that many logistics industries have already carried out investments in China not only with the aim of developing manufacturing activities-China as "factory of the world" [50] - but also to improve distribution systems. A probable scenario would therefore resemble one in which China develops as a consumer market, leaving some economic gains in developing manufacturing activities on the ground to the benefit of other countries; and while the share of domestic consumption on Chinese GDP is still low (around one third), ${ }^{5}$ and its increase over time will be at least gradual, from a logistics viewpoint, a dramatic development in distribution logistics over traditional production logistics will take place.

Note also that:

- China is already playing the role of hub of productionlogistics networks in East Asia, especially with regards to countries such as Japan and South Korea [17];

- already today, from a detailed analysis of Chinese statistics information regarding trade flows, one can realize how the Chinese economy is not abnormally export-led [1, 35] (Fig. 3) ${ }^{6}$ :

Although recent events, such as workers strikes at the Honda manufacturing plant in Foshan, should be viewed as a relevant political change, a strong cultural sense of community, effective tools of political control and public order, make the potential for domestic political instability still quite unrealistic for China. ${ }^{7}$

More issues emerging from the "China question" [46] are: if future scenarios will show a disappearing of China as the so-called "factory of the world" [50], where will production activities move? Might the locus of low-cost production shift to other countries [46]? Could we revert back to modest-cost regional production centers? What will be the relationships with consumer markets? The main point here is whether or not other countries could replace today's China as the world's main production market. Will there be another China [50]? Some of the possibilities on the table are:

\section{- Africa;}

- Mexico and Latin America/Brazil as possible production platforms for the North-America markets;

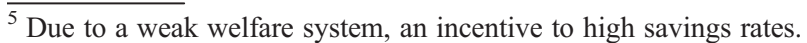

${ }^{6}$ Statistical analyses of this kind are quite complex, however they stress the need of subtracting part of import flows from other countries - mainly Asian ones - when considering the overall export values of China. A relevant part of China export activities consists of goods that are imported from other Asian countries and not "truly" manufacturing in China.

${ }^{7}$ Clearly, we are dealing with a highly uncertain scenarios (consider, for instance, the case of Russia..)
} 


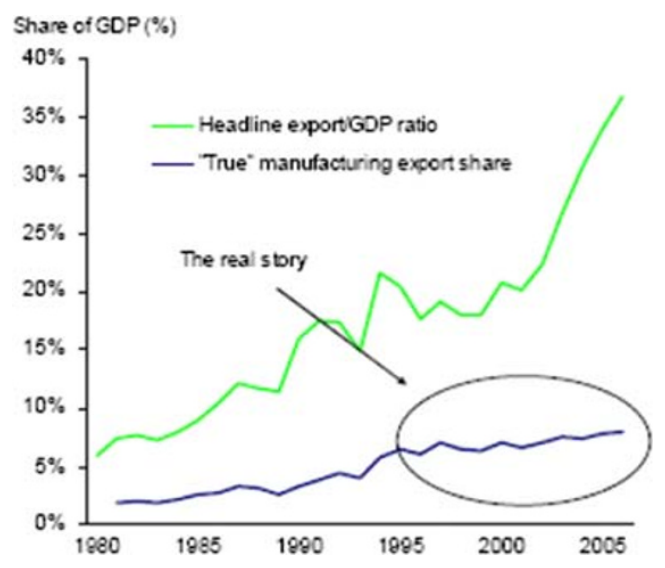

Fig. 3 China's exports. Source: [1]

- Eastern Europe and Russia as possible production platforms for the European markets;

- Other specific opportunities such as Japan, South Korea, Thailand, Cambodia, Vietnam, Indonesia.

From our focus groups, we get the following results:

- the role of Africa as a continent is unanimously deemed implausible. Potentially, Africa represents the only continent having some quantitative dimensions (space, population, etc.) similar to those of China. ${ }^{8}$ However, with its lack of political control and precarious domestic stability, aggravated by a demographic sprawl on the territory, Africa could hardly represent a China alternative. Unlike China [23], where the political control is impressive, Africa's government of different ethnic groups will possibly remain an unresolved issue ultimately hindering economic development. However, while this could be true at a continent level (which is meaningful when comparing to China as a whole), really significant regional developments will and are already taking place in Africa, ${ }^{9}$ fostering economic development;

- Brazil is indicated as a relevant future market, especially for distribution logistics activities;

- similarly, Mexico is viewed as a potential production market as it features a good availability of low cost workers, is included in the NAFTA agreement and is located close to the North-American markets ${ }^{10}$;

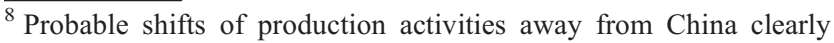
should take into account some quantitative dimensions of the Chinese market

${ }^{9}$ See, for instance, the development of the textile-clothing industry in the Maghreb region and of the food industry in Egypt.

${ }^{10}$ As many experts suggest, "the US have some sort of China in the backyard". It should also be noted that Mexico is among those countries less suffering the consequences of the financial crisis (this being a sign of financial stability) and it is indicated as a potentially important final market.
}

- other probable alternatives to China indicated by our experts are countries that already have strong manufacturing and logistics relationships with China (often off-shore locations of China manufacturing activities) - Cambodia, Vietnam, South Korea. They will possibly play a marginal role especially in the medium term. ${ }^{11}$ In fact, they are small and legal constraints over production activities are becoming increasingly stricter;

- due to its quite closed economic system, aging population, high demographic density and unfavorable geographical features, focus group participants don't view Japan as an important player. Some focus group participants say that it could be an adjuvant contribution to China. However, Japan surely holds a good technology endowment.

Additional issues to be addressed about the role of emerging markets concern to the way in which one can combine the requirements of global markets with the need of designing fast and flexible logistics networks [46]. One of the solutions is to rely on standardization of both logistics processes and products in order to streamline response to shifts in logistics chain flows while fulfilling market requirements. This happens, for example, at Wal-Mart in US markets, whose logistics chains comprise products quite similar to one another. By contrast, when market requirements turn out to be more sophisticated and demanding-for instance, in the EU area-logistics network design becomes more costly, and a number of depots or distribution centers on the territory must be planned to be closer to the final markets. A highly possible scenario may be one based on a regional model of production-logistics-consumption activities, where logistics chains will be shorter. Shorter logistics chains imply more reactive logistics models more suitable to time-sensitive market requirements. Furthermore, shorter and more reactive logistics chains may favor a further sophistication in market preferences and consumer choices.

\subsubsection{The balance of global economic power}

Another economic driver of change is the tendency toward a rebalancing of economic - thus, political and militarypower worldwide [22], whose evidence is given by the decrease in world's GDP share in areas such as the US and Europe and, by contrast, by the dramatic increase in GDP share in countries like China, India and Russia (Fig. 4).

Concerning this driver, major logistics questions emerge: to the extent to which the above mentioned areas will become more relevant as consumer markets, what will happen

\footnotetext{
${ }^{11}$ For instance, Vietnam is often indicated as the next China, since it has a very cheap workforce (its per capita income is less than a third of China's). Some global companies moved there, such as Intel. But workforce is highly limited in number.
} 


\section{Growth of regional GDP per capita}

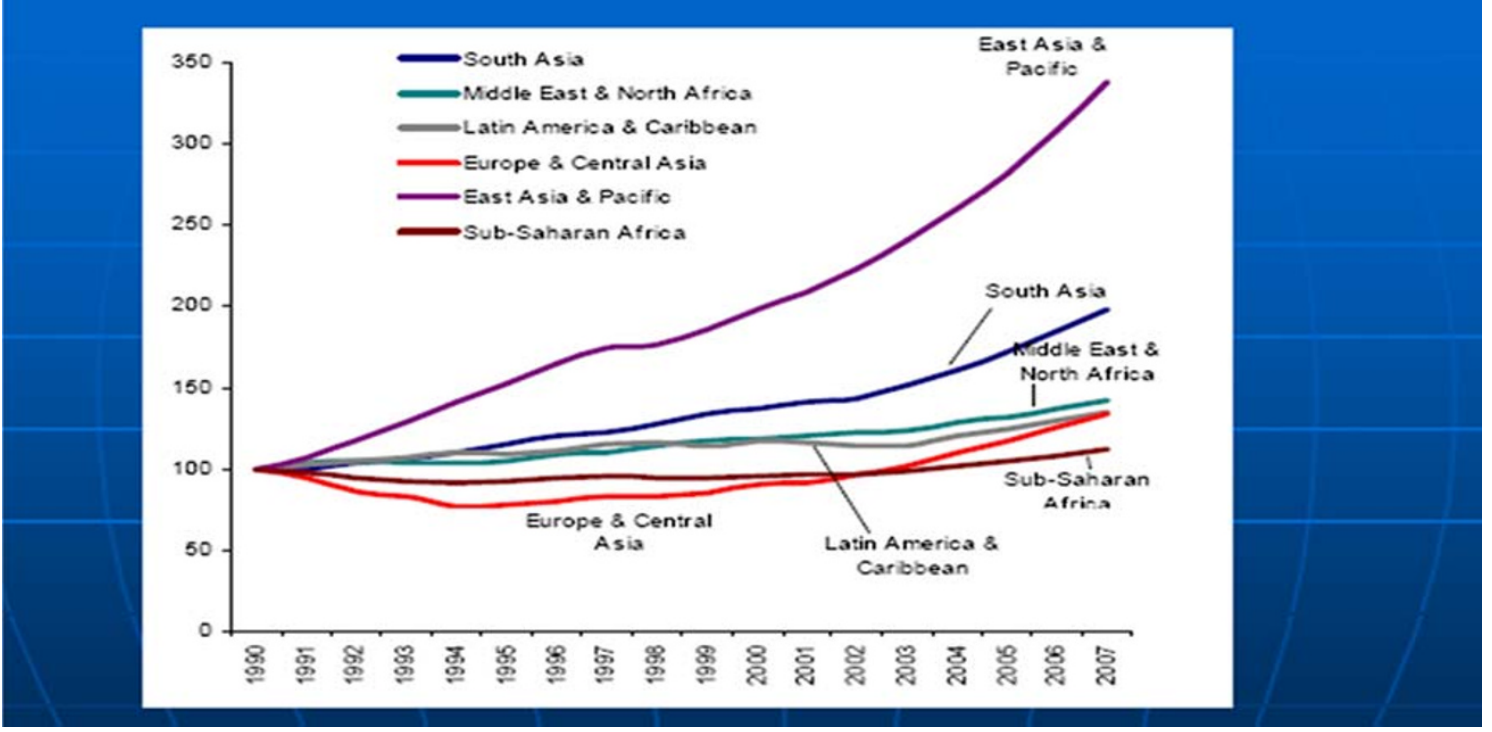

Fig. 4 Per capita GDP growth. Source:[33]

to the design of logistics networks feeding those markets? What could be the role of Western economies?

To some degree, the distribution of economic power among the so-called three empires (US, China, EU) will depend upon the influence they will exercise on the Second World countries, in particular on:

- India [6], which still remains, in many global players' view, a would-be opportunity, due to its high poverty rate and difficult geopolitical relationships with neighboring countries;

- Russia, which is experiencing a strong decline in population (in 2025 Russia population will be similar to that of Turkey) and a strong pressure on its natural resources by China at its Eastern borders. For some experts, such a pressure could induce a sort of Chinese hegemony. Moreover, Russia is among those countries that suffered significantly the consequences of the global financial crisis;

- countries with significant oil endowment - such as Venezuela, for which Europe represents the first foreign investor, while China is strongly developing transportation infrastructures there;

- Iran, increasingly under Chinese influence (as China's access to the Persian Gulf) and less dependent on Western investments.

Major results we get from our focus groups are:

- as China increases its share of world GDP, it will no longer "disturb" European producers from a logistics point of view, in a sense that its domestic market will be a major target for manufacturing activities. Indeed, such extra demand is clearly welcome particularly in the current period of global crisis where it acts as a trigger for production and trade from more steady economies (EU—-see the recent example of Germany-and the US in particular) [50];

- an uncertain scenario looms over India. India has been perceived as a relevant opportunity for a long time, ${ }^{12}$ however it is still at a potential level, although it is showing relevant growth rates. Unlike China, India remains somewhat unattractive to foreign investors;

- Russia - although opinions vary - probably won't be a weak global player, given its good technology and natural resources. The idea of a Russia under some sort of Chinese hegemony is regarded, in the view of our focus groups experts, as not possible. Yet, a regional model of production-logistics-consumption could be the case also for Russia.

\subsubsection{The role of the trading blocks}

Some sources [26] identify 3-4 relevant trading blocks on a global level: that is, Europe, US, Asia/Japan, China. They will be characterized by significant:

- in \& out trading barriers;

- intra trade development.

Again, the main logistics question is: what will be the consequences on global logistics networks design? Some of the recent instability events - like the economic and financial crisis, the governance of migration flows, terrorism

\footnotetext{
${ }^{12}$ Also for the availability of handcraft-style production capabilities, high-skilled human resources and a largely young population.
} 
threats, etc.- - seem to quite strongly favor the above scenario by means of a number of constraints imposed on the movements of people, goods, information, etc. [47]. Also, such events make logistics networks rather insecure. ${ }^{13}$

Main results from our focus groups consist of two key drivers:

- a regionalized pattern of logistics flows within the macro-regions should be the prevailing model at spatial level;

- however, probable regulation barriers (e.g., duties, etc.) will not play a relevant role. Rather, economic opportunities will prevail [43]. In other words, the development of more localized production-logistics-consumption models will be induced by the exploitation of strategic economic opportunities rather than by the imposition of political constraints.

\subsubsection{The role of the financial and economic crisis}

The role that the current financial crisis will play on future logistics scenarios clearly cannot be neglected. The most relevant aspects perceived by operators basically refer to its duration, while the general impact will be concerned with the magnitude of logistics flow among the different areas.

It is out of the paper's scope to even try to address such a crucial issue globally. We could simply refer to a recent study by the Federal Reserve-Morgan Stanley Research in which short-term (one year), medium-term, and long-term scenarios were built to assess the potential impact of the crisis. The study termed a potential exit from the crisis in the short term simply implausible. The reason, one reads, is quite trivial: "too much debt"; the problem is simply "too big in size". We reasonably think that the effects of the current crisis will last for still some time ${ }^{14}$.

The economic crisis will also generate relevant impacts on the market structure of logistics, most likely producing a strong tendency toward oligopoly. The economic crisis represents for structured companies a big opportunity for shopping, whereby increasing market concentration. A number of strategic alliances among companies and mergers will be carried out and they will aim at improving the overall efficiency of logistics processes and reducing idle capacity. In this respect, many global players underscore how the current crisis has certainly produced negative effects on the economy. However, one should remember that an

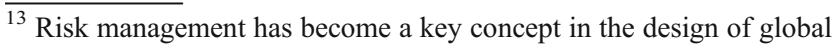
supply chains since the September, 11.

${ }^{14}$ From our focus groups it emerges that companies are mainly worried about the question: are we at the beginning or toward the end of the crisis?
}

important excess of overall capacity ${ }^{15}$ worldwide has been in place for quite a long time. Therefore, the crisis can also be partially explained by the economic cycle.

Another comment from our focus groups is that the crisis will induce strong incentives to operators toward modal shifts, in particular toward less costly and efficient modes of transport (railway and maritime transport in the first place). In fact, operators will focus progressively more on the efficiency of transport operations, meaning consolidation of flows and cost savings.

\subsection{Technological drivers: the role of IT}

IT is important because logistics networks will be more and more characterized by visibility and virtuality (distributed entities) in all their relevant elements: flows, stock, assets.

A complete review of IT systems related to freight logistics at EU level can be found in [16]. IT systems refer to the combination of ICT (Information and Communication Technologies) in order to optimize transport efficiency and operational sustainability. More precisely, the Freight IT systems can be defined as "advanced ICT systems aimed at simplifying and automating freight operations" [16].

The field has seen substantial development in the last 15 years. The introduction of sophisticated systems and technologies collecting enormous amounts of data about current status as well as the various logistics planning parameters concerning the operation of freight transportation and logistics systems, allow to transmit these data to control centers and data bases held at authorities, carriers and other operators.

Initially, Freight IT systems used mainly stand-alone applications [16] that can be largely classified in the two categories of commercial operations and fleet management systems. Most of the technological drivers were developed in the nineties' and early 2000's. The core of such tech drivers are: mobile transmission technologies (such as GSM), GPS (Global Positioning System), mobile internet, the XML standard, various guidance and navigation systems, onboard sensors, systems and hardware for vehicle or load unit identification (e.g., RFID).

Now, these drivers are transforming the EU industry and having clear impacts on the logistics systems in terms of:

- availability of integrated information and services, based on the improved availability of internet standards and infrastructure;

- new intermediary systems offering services such as freight matching, transport auctions, rate quotes, etc.;

\footnotetext{
${ }^{15}$ Some experts suggest a ratio between production capacity and consumption levels in the order of 2,5:1.
} 
- integrated onboard computer systems and home-base systems that are interconnected via data links based on GSM/WAP or mobile internet;

- new and innovative fleet management and monitoring capabilities.

For future logistics needs, Freight IT systems should be characterized by the so-called four "I"s -Integrated, Intermodal, Internet based, Intelligent - as the ingredients of the Freight Intelligent Transport System.

When dealing with global logistics scenarios-building, one relevant question is whether Freight IT systems will be a real competitive advantage [46] or they will become a sort of ubiquitous good-a public good in a sense-in future scenarios. Will we face a world-is-flat scenario, that is, a total connectivity one [27]? Those who conceive IT developments as neutral drivers justify their view by saying that IT tools will be easily replicated in the future; therefore they will no longer constitute a sustainable advantage in the competition arena.

No doubt Freight IT systems will emphasize the speed of information management flows, whereby logistics networks will be increasingly planned and managed on real-timefaster, flexible and responsive. Our results indicate that we need to distinguish between basic IT systems and advanced ones. The former could be actually seen as a sort of public good; but not so the latter. Indeed, for innovative IT systems, global players are firmly convinced that they will constitute a strong competitive advantage. Specifically, major opportunities for competitiveness won't be found in owning IT tools as much as in using them appropriately. That is, competitiveness will depend on the know-how of logistics information management concerned with flows and stock. Some of the most relevant IT advantages will lie in developing process innovations rather than product ones.

\subsection{Demographic factors}

Major demographic trends having impacts on the logistics network design in the medium term will be:

- the aging of population in the Western world and developed countries, and generally speaking the change in the demographic structure of population;

- the increase of world population.

The first point - see Fig. 5 for the US case [52] —implies a change in market profiles, e.g. new types of products will be required and there will be a larger share of services. The open logistics question is: will this be a new challenge for producers and logistics operators?

It is quite clear that the EU area will be among those most affected by this trend, e.g., where major qualitative changes of market demand will occur.
Another qualitative change in demand in the EU area will be determined by the impact of immigration policieswhether they are going to be more or less open and friendly. The degree of openness in such policies will determine cultural and ethnical changes in market profiles.

From a strictly quantitative point of view, estimates show that world population will be of some 8 billion people by 2020 (it is currently around 6.5). This means a dramatic increase of flows worldwide and, at the same time, a strong pressure on resource utilization, which in turn would produce a strong incentive toward efficiency (and creativity) by industrial and logistics systems.

In the logistics field, one can also highlight the increasingly relevant role of the tourism sector relative to the increase of world population. To the extent to which economic growth will spread at global level, resources that "cannot be moved" will be required by a larger number of tourists. This will determine specific requirements for logistics (procurements, distribution of consumer goods, etc.) and for production as well (regional industrial systems). The role of the tourism sector in regional economies will thus be enhanced.

\subsection{Regulation and sustainability}

Because of its link to modern social requirements inclined toward a more environmentally-friendly economy, regulation consists of an important driver. New regulatory trends will certainly influence some logistics aspects, from product design to logistics network design, through strategies and practices such as:

- green product design;

- reverse logistics;

- total lifecycle assessment;

- $\quad$ selection (also, at spatial level) of main suppliers;

- investments and technologies in production and distribution;

- choice of procurement materials;

- choice of modes of transport.

Additional issues related to social responsibility determining impacts on strategic logistics scenarios refer to human rights and a better quality of life. The former has to do with the impact on logistics choices such as suppliers' selection and sourcing locations. The latter relates to qualitative changes in market demand, whereby fostering specialization of logistics chains.

Since it represents an historical trend of globalization, as already happened in (now) developed countries, human rights legislation has been applied in an increasingly greater number of areas and markets.

Another issue is whether the so-called green logistics is still perceived as a corporate responsibility rather than as a market competitive advantage. The prevailing opinion from 
Fig. 5 US demographic trends. Source: [52]

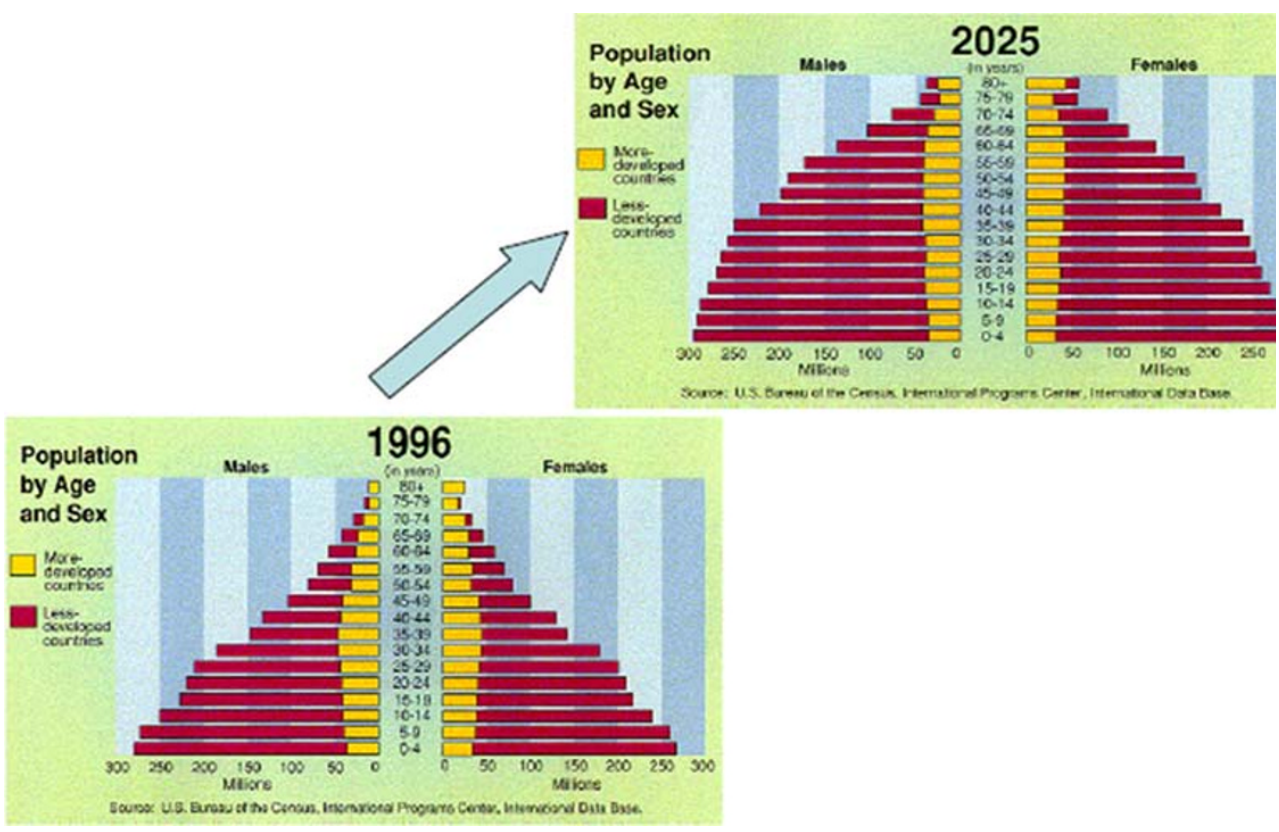

our focus groups is that it is still mostly a matter of corporate responsibility.

\section{Strategic scenarios of global logistics: some proposals}

As previously mentioned, scenario-building (SPA) methodology requires combining drivers - whose meanings and roles have been specified and discussed previously - to produce and defining a number of scenarios (states of the world).

In this section we first discuss some preliminary results and fix some points that come out from the analysis of major drivers carried out so far through literature, focus groups and interviews.

Such preliminary results and milestones are then useful to effectively combine drivers in order to design scenarios. As we will see, we end up specifying a prevailing macroscenario of global logistics within which two sub-scenario components could possibly play a role.

Remember that each scenario, generally speaking, is a coherent picture of a probable state of the world. In addition to the Shell Corporation's back-to-history case, some logistics companies effectively use the SPA. For instance, UPS used similar techniques to depict scenarios to 2017 [46]. Starting from the analysis of some 30-40 factors, UPS reduced them to a couple of relevant dimensions. Four probable scenarios were finally derived on the basis of manageability and relevance for the company.

Clearly, in our study we do not adopt a company-based vision of future logistics, but the remark is important to see how, at the very end, even if the number of drivers initially considered are quite high, final scenarios end up to be just a few.
Preliminary results show us how the cost of strategic resources - most importantly energy ones - will play a determinant role in the re-designing of global logistics networks, leading them toward more efficient and shorter ones. Simultaneously, specialization will be a major requirement for production and logistics chains, as well as a strong pressure for efficiency. Furthermore, it will be strongly necessary for companies and institutions to be aligned to international benchmarks.

The growth of world population will be another determinant driver. It will imply, on one hand, an increase in consumption levels, and, on the other hand, an increasing pressure on resource utilization thereby fostering a trend toward more efficiency in all sectors of the logistics chains.

The current economic and financial crisis will certainly determine a decrease of global flows that will last for quite some time, and more concentration of logistics markets. However, it will not constitute a structural economic change.

Innovation processes will follow a diffused model on global scale, while the role of IT systems will be very important for competitiveness as long as it will refer to advanced and innovative systems managing logistics flows and information.

Moreover, as global growth spreads, requirements in terms of regulation, sustainability, green logistics and human rights issues will become more and more important.

Overall, the scenario-building process (e.g., combining drivers) highlights the following prevailing macro forces determining the future patterns of logistics networks:

- a shortening of logistics networks (by strategic redesign);

- a strong pressure toward efficiency, specialization and sustainability.

Transportation flows dynamics will be linked to GDP and population growth (and temporarily to the impact of the 
economic crisis) and they will develop mainly within the most relevant macro regions. Core macro areas/regional systems at global level (macro logistics platforms) can be identified as follows:

- the American system, centered around Brazil, Mexico and the US, with a relevant role in the future ${ }^{16}$;

- the Chinese system, mainly made up of production networks in which China will be the most relevant hub node along with some other satellites' East Asia countries (Japan, South Korea, etc.). It will develop mostly as a major consumption market in the future;

- the India system, playing a highly potential role even if with some uncertainties;

- the EU system, again a relevant one above all to the extent to which immigration flows will be regarded as a fundamental production and consumption driver [34], will face important challenges to governing the dynamics of immigration flows. As it will be able to seize upon such an opportunity as an economic driver, both an industrial future and an important role as a consumer market (trends toward aging of population and consumption stagnation will thus be counterbalanced) can be envisioned within an enlarged EU area;

- the Russia system - being of relevance, however with a more steady path of development (e.g., due to decline in population).

These trends and forces will determine a shift from the current model of global logistics based on a strong asymmetry of spatial distribution of logistics platforms - centered around the role of the Chinese economy as "factory or workshop of the world" [50] - toward a global-scale model characterized by a more symmetric spatial distribution of production and logistics platforms functionally linked to final markets as the most likely scenario (a sort of logistics sprawl) [38, 50, 51]. Moreover, due to the increasing pressure on global resource exploitation, activities will have to be highly efficient and specialized, before being less energy-consuming.

As a matter of fact, from a spatial viewpoint, the current model has determined a trend toward a strong asymmetry in the spatial distribution of logistics nodes and platforms and a dramatic increase of long-haul flows on the East-west axis. In the future, on the one hand, China will benefit from a steady economic growth and will consequently experience a positive wage and per capita income dynamics, while suffering from constraints due to supply of labor and aging population [50]. On the other hand, no "China substitute"in terms of major manufacturing market—can realistically be envisioned.

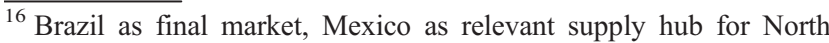
America.
}

Within such a more dispersed macro-model at global scale, two major components - linked to the above mentioned forces - will play a role:

\section{- a regional or localized scenario component (LOCAL scenario);}

- a globalized scenario component (GLOBAL scenario).

The LOCAL scenario is characterized by the fact that due to the effects of some drivers - in particular, the energy costs hindering the development of large-scale networks, the growth of the Chinese economy and the absence of realistic alternative to the current Chinese role as "factory of the world" [50] — production platforms will move close to consumption sources. ${ }^{17}$ The LOCAL scenario will shape a trend toward a regionalization of economic and logistics systems (through a re-location dynamics of nodes), in which short or medium-range flows will be the most dynamic ones.

Conversely, in the GLOBAL scenario [56] the ultimate result of the (re)location process of logistics platforms is not necessarily one in which production sources will move closer to the consumption ones. In fact, the increase in costs due to scarcity of resources will impact all types of costsprocurement, production and distribution ones [21]. The final result will then be an overall increase in the costs of final goods and a resulting change in relative prices. The role of transportation costs will remain more or less the same proportionally to other kind of costs. In such a case, the driving and prevailing criteria for logistics networks design will be a premium effort toward efficiency and specialization.

Moreover, the role of transport should be correctly conceived in an economic and timely manner rather than in purely geographic terms. One can easily verify that transport costs have been very low for a long time (actually, low transport costs triggered globalization [28]). Thus, an interesting question could be: how much should transport costs increase - due to the surge of energy prices -before they can drop back to pre-globalization levels? The margin may be perceived to be pretty relevant.

Regarding transport costs one should distinguish between the start-up component - related to fixed costs and generally predominant - and a variable one, which very often tends to be less relevant. Seemingly, a more widespread diffusion of economic growth worldwide can be envisioned in relation to an increased per capita income. Thus, such a scenario highlights how efficiency in all the sections of the logistics chain (procurement, production, distribution) will be the key competitive element.

Conclusions - for the GLOBAL scenario - are that we will certainly see a spatial redistribution of production platforms, however they will not necessarily be located near final

\footnotetext{
${ }^{17}$ In a word: "one will produce where there is market demand".
} 
markets. In fact, the key variables - in a context in which transport costs will have a relative impact - will be production and logistics specialization and efficiency. The prevailing model will be a more spatially distributed/diffused one, but it will be based on a rationale of specialization and efficiency. In a word: "one will produce in the more specialized and efficient areas and will (potentially) distribute to major global markets". Manufacturing and logistics activities will be spatially concentrated in the most efficient and specialized regions and long-haul transport flows will be potentially fostered. Potential global leaders could then emerge in certain areas, thus implying a spatial concentration of innovation processes and of volumes (economies of scale).

In this context we are convinced that the current "factory of the world" [50] — China — will be able to play a relevant role [2]. Since it is based on Chinese competitiveness as related to low cost products on global markets (in which transport costs basically turn out to be irrelevant), in a way, the LOCAL scenario would imply a neutralization of China's role. Conversely, the GLOBAL scenario highlights a role of China as a specialized production-logistics platform. China, in addition to showing internal growth and increasing labor costs, is also strongly specializing in many sectors. Coupled with the capability of exploiting huge economies of scale in production, such a scenario configures a strong competitive role for China. ${ }^{18}$

In any case, the driving criteria for optimization of logistics networks design in both types of scenarios will be somewhat different from the one currently in place. Logistics networks design will be triggered and focused on the maximization of the contribution margin of logistics on different markets rather than on a mere minimization of production costs (labor costs in particular). ${ }^{19}$

Importantly, it should be noted that in the GLOBAL scenario the development of potential global leaderships will be hindered by the customer service levels set by markets. The potentially global nodes of excellence will have to cope with the temporal constraints imposed by markets and customers - that will be more and more demanding and time-sensitive whereby requiring reactive logistics networks and vicinity to suppliers ${ }^{20}$ and customers.

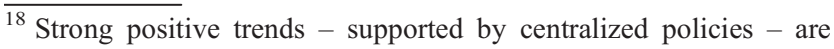
already under way in non low cost sectors. Notably, spatial planning has a strategic role in such policies and the EDU sector is under strong development. Also, consider some recent statements of the Chinese government about the availability of a production capacity to be sufficient for the whole global consumption...

${ }^{19}$ That is, looking at the maximum difference between market revenues and logistics costs in each market area. Some industries - such as "white" and consumer electronics - have already supported such a strategy.

${ }^{20}$ See, for instance, some trends in the US apparel industry relatively to the relocation of manufacturing platforms from Asia to Mexico and the Caribbean, let alone, in Europe, the landmark example of Zara.
}

Note also that the efficiency requirement-which is the major driving force in the GLOBAL scenario - must not be seen as less important in the LOCAL scenario. Indeed, various opportunities of growth and development related to the closer-to-home trends for production and logistics activities - for instance, in Europe - will have to be dramatically supported by effective policy actions focusing on efficiency targets. It will be necessary to re-design the productive and logistics systems so as to align them to international standards leading to maximum efficiency. In this context, a strategic policy tool will be spatial planning, since many global best practices - the Chinese and the European ones as well-are the results of incisive and effective choices in the field of spatial planning related to logistics. One should raise the question whether or not some guidelines of modern spatial planning can be found in the decision-making processes of public bodies already today. Or, conversely, if we are facing obsolete models of spatial and logistics development. Clearly, the question remains open. As a matter of fact, economic and strategic analyses should go hand in hand with land-use ones aiming at (re) defining a model of production and logistics systems in which the environmental variable must play a decisive role.

\section{Conclusions}

\subsection{Global Spatial Logistics: some new insights}

To summarize the main results, we would say that from the disappearing of an asymmetric global model of spatial logistics and manufacturing, a macro-model characterized by a more symmetric spatial distribution of production and consumption platforms can be seen as the most likely macro-scenario - SGLM: Symmetric Global Logistics Model. Generally, global flows will steadily increase in the future, as it results from the driver analysis. ${ }^{21}$

Sub-scenarios can then be built related to the way in which such a diffused model can develop in relation to the prevailing forces or macro drivers, in particular by identifying:

- a LOCAL scenario: production will be near consumption;

- a GLOBAL scenario: production will not necessarily be near consumption.

We think that the two scenario components will ultimately determine a prevailing (most likely) scheme of regionalized systems, along with the possible development of high degrees of specialization (or, should we say, super-

\footnotetext{
${ }^{21}$ This is the combined result of the role of the economic and financial crisis (that should be considered relevant but not structural), the development of emerging markets and the growth of global population.
} 
specialization) in specific industrial and logistics sectors, in which global leaderships could emerge (conditional on market constraints in terms of customer service). The two scenario components should then be viewed as complementary, since we would have a prevailing and more likely pattern (LOCAL) and some probable GLOBAL trends in specific industries.

The macro-model of global spatial logistics-SGLMand its two possible logistics dynamics and features (one more likely to occur than the other) represent a major result of our study, compared with previous studies. It clearly does not reflect the common vision of an endless trends of globalization in manufacturing and logistics activities since, for instance, it supports generally the shortening rather than lengthening of logistics chains worldwide, and the (macro) regionalization of manufacturing and logistics activities rather than globalization. By contrast, $[12,37]$ underline the character of Global Production Networks (GPNs) as being more and more fragmented at global level. Regional developments, however, are indeed considered as they are embedded in global networks [9]. Also, it is highlighted how GPNs rely more and more on global distribution networks [5], while a further extension of globalization is seen in the development of global logistics providers. It is recognized [37] that the conditions behind globalization that were supported by the setting of long distance transport chains will change in the future. However, emphasis is put merely on the role of energy prices as they will determine a modal shift toward more efficiency modes of transport.

Looking at the stock-flows' patterns and logistics network design in the two scenario components within the SGLM one can envision the following picture (Figs. 6, 7) 22 :

- major geo-economic areas (to be seen as probable locations of procurement/production/distribution platforms) and regional systems will be basically the same in both scenario components;

- looking at flow patterns, while in the LOCAL scenario component (shorter logistics chains) internal flows will show higher growth rates than inter-change flows (e.g., among geo-economic poles), the opposite will be true with regards to the GLOBAL scenario (interchange flows' growth rates will be potentially higher-longer logistics chains). Remember, however, that we deem the GLOBAL scenario component less likely to occur, since it will be potentially restricted to specific industries. As

\footnotetext{
$\overline{22}$ The two maps clearly do not represent a detailed logistics network design, since they aim at giving a macro/aggregate representation of nodes (platforms) and flows at global level. However, note that in our study we take a logistics approach since we deal with logistics variables (e.g., nodes, flows) and activities (e.g., procurement, production, distribution). For instance, geo-economic areas show where procurement, production and/or distribution nodes will be located.
}

said, the two maps should be read as complementary within the overall SGLM.

\subsection{European's logistics competitiveness: some strategic impacts}

Some clear-cut strategic impacts on the European logistics stems from the above scenario analysis and the development of the SGLM. What will be the specific impacts of the SGLM on Europe? What will be the major logistics platforms (procurement, production, distribution) in Europe and the dynamics of transportation flows?

First of all, the shortening of logistics chains and the related strategic re-location of logistics and production platforms along with the increase of global competitiveness in specific industries would result in a reinforcement Europe's role as production/industrial world region. Two caveats should be highlighted here: first, Europe already has a relevant role (in absolute terms) as global market; second, economic growth in Europe will be lower than in other emerging economies.

More specifically, the LOCAL scenario component will depict a strategic trend toward a re-location of production platforms - as well as logistics ones- in the EU area functionally related to EU distribution logistics and EU final markets. According to structural trends already under way, the future most attractive areas for production and logistics will be those of North Africa and Eastern Europe, ${ }^{23}$ with relevant end-customers Western European markets. A number of global logistics players (in particular, integrators and shipping companies) are already experiencing ${ }^{24}$ relevant re-location processes of logistics platforms toward those regions. ${ }^{25}$

Therefore, we could take note of a partial substitution effect in Asian relationships with intra-MED and Eastern Europe ones; that is, a new partial rotation of major EU flows from East (Asia) to West (MED and Eastern Europe).

Moreover, procurement flows distances will be shorter, e.g., inbound logistics will be based on regional suppliers (in contrast with the current prevailing model of long-distance suppliers) and, again, North Africa and Eastern Europe will be the most interesting areas of concern. It is believed that a model of turn-key suppliers will be the predominant one,

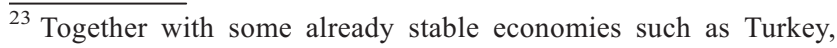
which, among other things, has been hit by the global crisis only partially.

${ }^{24}$ For instance, Maersk.

${ }^{25}$ Some examples are those of the shoe-makers sector with regards to the development of hubs in Budapest, Timisoara, Poland and partly in Bucarest. Still in the shoe-makers and textile-clothing sector relevant growth is under way in Tunisia and Morocco. Moreover, in the food sector crucial regions turn out to be those of Egypt, EAU and Saudi Arabia.
} 
Fig. 6 The LOCAL Scenario. Source: this study

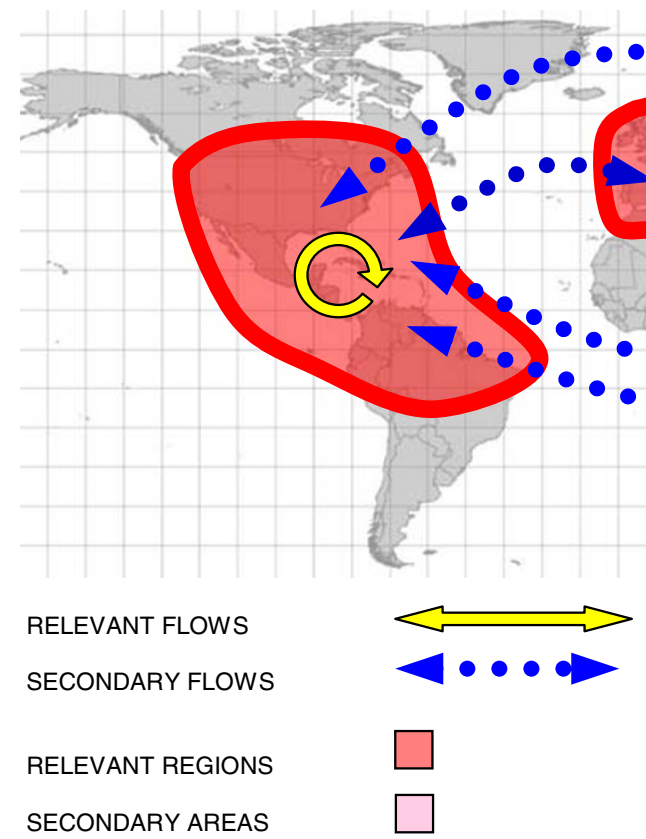

while the previous model of suppliers of semi-finished products will progressively come to an end. Such trends will clearly impact unitized traffic in the EU area.

From a quantitative point of view, the development of transport flows will be linked to the overall growth rate of the EU economic market. We can recognize a low scenario (stability) and a high one (positive trend mainly induced by immigration flows). According to some estimates of GDP growth [42], low scenario would consist of a $1.7 \%$ of annual growth, while the high one would imply a $2.4 \%$ annual growth rate.
Given that, in the LOCAL scenario, European logistics networks design will rely on Eastern and Mediterranean production and procurement platforms, while focusing on Western European final markets, strategic impacts on transport flows will consist, for instance, of:

- a strengthening of multi-modal transport flows toward Western European final markets (main markets will be Western ones);

- a strengthening of multi-modal (mainly land-based) transport flows from Eastern Europe (since Eastern procurement and production platforms will develop);

Fig. 7 The GLOBAL Scenario. Source: this study

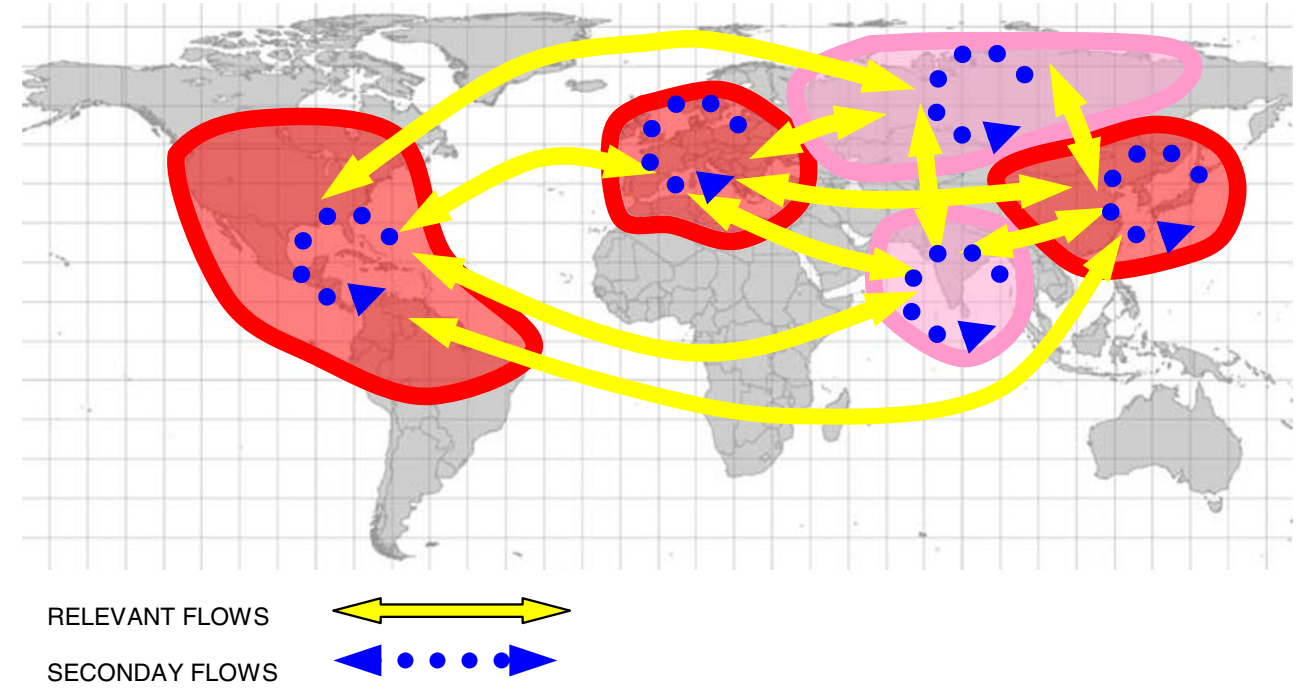

RELEVANT REGIONS

SECONDARY AREAS 
- a strong growth of inbound logistics flows on the Northsouth (MED) axis using maritime services (since MED procurement and production platforms will develop).

The LOCAL scenario will provide for relevant market opportunities for many logistics chains of the EU market and suggest the situation of a partial "capturing" of market shares from Asia, particularly from China.

The GLOBAL scenario, instead, identifies probable European best practices with reference to specific logistics chains. In this case, Europe would result being specialized in some sectors and compete worldwide. Unlike the LOCAL scenario, the range of production and logistics opportunities (in terms of type of products) is restricted to specific industries, while potential market areas broaden, not being restricted to the sole EU market. Therefore, major opportunities in terms of transport flows development are:

- a high potential growth of maritime flows to all the most important geo-economic market areas worldwide (thanks to the increase in global competitiveness of EU in certain industries). Nevertheless, it has to be noted that long-haul East-west relationships will face deep restructuring processes of supplied services. Overall, the MED will play a relevant role especially for the development of intra-MED services and direct calls (also, with medium size vessels ${ }^{26}$ ) while transshipment services will be operated more efficiently [31];

- a strengthening of multi-modal transport flows toward Western European final markets (Western European markets will still play a big role);

- a strengthening of multi-modal (mainly land-based) transport flows from Eastern Europe (since Eastern procurement and production platforms will develop);

- a strong growth of inbound logistics flows on the Northsouth (MED) axis using maritime services (since MED procurement and production platforms will develop).

Quantitatively, we would argue for a standard increase of commercial and transport flows linked to global GDP growth, disaggregated by macro-regions (on average: $+3.8 \%$ annual growth in the high scenario, $+2.6 \%$ annual growth in the low scenario [41]). Such figures should then be summed up to the potential export market shares captured by Europe thanks to the specialization strategy. From this standpoint, by analyzing the most important trade axes (EU-America, Asia-America, EU-Asia) one clearly realizes a very strong potential.

As general conclusions of our analysis, we believe that, taking into account the differences between the two scenario components mentioned above, Europe will play a relevant

${ }^{26}$ See, for instance, the Evergreen case. role in the global logistics scenarios - although less important with respect to major emerging economies - by fostering its development as production-logistics hub of landbased and maritime flows (mostly European or global ones depending on the scenario component) strategically relying on production and procurement platforms in the MED area and in Eastern Europe.

Open Access This article is distributed under the terms of the Creative Commons Attribution License which permits any use, distribution and reproduction in any medium, provided the original author(s) and source are credited.

\section{References}

1. Anderson J (2007) Is China export-led? UBS Investment ResearchAsian Focus

2. Antweiler W, Trefler D (2002) Increasing returns and all that: a view from trade. Am Econ Rev 92(1):93-119

3. Arvis J-F, Mustra MA, Ojala L, Shepherd B, Saslavsky D (2010) Connecting to compete 2010 - trade logistics in the global economy. The World Bank, Washington DC

4. Broadman H (2006) Africa's silk road: China and India's new economic frontier. World Bank, Washington DC

5. Capineri C, Leinbach T (2003) Globalization, E-economy and transport. Growth Change 34(4):385-389

6. Chakravorty S (2007) Made in India: the economic geography and political economy of industrialization. Oxford University Press

7. Chermack TJ, Lynham SA, Ruona WEA (2001) A Review of Scenario Planning Literature. Futur Res Q 7(2):7-32

8. Ciccone A, Peri G (2006) Identifying human capital externalities: theory with applications. Rev Econ Stud 73(2):381-412

9. Coe J, Hess M, Yeung H, Dicken P, Henderson J (2004) Globalizing regional development: a global production networks perspective. Trans Inst Br Geogr 29(4):468-484

10. Council of Supply Chain Management Professionals (2008) 2008 3PL Provider CEO Perspective. Annual Global Conference, Denver, Oct. 2008

11. Denali Consulting (2002) Logistics trends-achieving supply chain integration. Los Gatos, CA

12. Dicken P (2003) Global shift, 4th edn. Guilford, New York

13. European Monitoring Centre on Change (2008) Trends and drivers of change in the EU transport and logistics sector: Scenarios. European Foundation for the Improvement of Living and Working Conditions, Dublin

14. Foster T (2005) Correct your supply chain vision to see what you need to see. Global Logistics \& Supply chain strategies 9(1), Nov

15. FREIGHTVISION-Sustainable European Freight Transport 2050. Project funded by European Commission, 7th RTD Programme

16. Giannopoulos G (2009) Toward a European ITS for freight transport and logistics: results of current EU funded research and prospects for the future. Eur Transp Res Rev 1(4):147-161

17. Gill I, Kharas H (2007) An East Asia renaissance: ideas for economic growth. The World Bank, Washington DC

18. Global Commerce Initiative, Capgemini (2008) 2016 Future Supply Chain. Capgemini Consulting

19. Godet M, Roubelat F, and Guest Editors (2000) Scenario planning: an open future. technological forecasting and social change 65 (1):1-2 
20. HOP! Macro-economic impact of high oil price in Europe. Project funded by European Commission-DG Research-6th RTD Programme

21. Hummels D (2007) Transportation costs and international trade in the second area of globalization. J Econ Perspect 21(3):131-54

22. International Monetary Fund (2008) World Economic Outlook 2008. IMF Research Department

23. Kanbur R, Xiaobo Z (2005) Fifty years of regional inequality in China: a journey through central planning, reform, and openness. Rev Dev Econ 9(1):87-106

24. Lakshamanan TR, Anderson WP (2002) Transportation infrastructure, freight services sector and economic growth. White Paper prepared for the U.S. DOT/FHA, CTS, Boston University

25. Lapide L (2006) The essence of excellence. Supply Chain Management Review, April, 18-24

26. Lapide L (2008) MIT SC2020 Project: Supply Chain Futures. SAPICS 2008

27. Leamer EE (2007) A flat world, a level playing field, a small world after all, or none of the above? A review of Thomas L. Friedman's the world is flat. J Econ Lit 45(1):83-126

28. Levinson M (2006) The box: how the shipping container made the world smaller and the world economy bigger. Princeton University Press

29. Lindgren M, Bandhold H (2003) Scenario planning: the link between future and strategy. Palgrave McMillan, New York

30. Lucas REB (2006) Migration and economic development in Africa: a review of evidence. J Afr Econ 15(2):337-95

31. Merlino M (2009) Mediterraneo: signori si chiude!. Logisticsa Management, n.198, ottobre

32. Moretti E (2004) Workers' education, spillovers, and productivity: evidence from plant-level production function. Am Econ Rev 94 (3): $656-90$

33. Nehru V (2008) Building a neighbourhood one policy at a time. JETRO Symposium Engaging East Asian integration: states, markets and movement of people. Tokyo, Dec. 9

34. Ozden C, Schiff M (2007) International migration, economic development and policy. World Bank, Washington DC

35. Prodi G (2007) Le PMI italiane in Cina: produrre per competere. L'Industria, n.3, luglio-Settembre

36. Ringland G (1998) Scenario Planning: Managing for the Future. Wiley \& Sons

37. Rodrigue J-P, Hesse M (2009) North American logistics. In: Global Logistics: New Directions in Supply Chain Management, 6th edn. Kogan Page, London
38. Rosenthal SS (2003) Geography, industrial organization and agglomeration. Rev Econ Stat 85(2):377-93

39. Schoemaker PJH (1993) Multiple Scenario Developing: Its Conceptual and Behavioral Basis. Strat Manag J 14:193-213

40. Schoemaker PJH (1995) Scenario Planning: A Tool for Strategic Thinking. Sloan Management Review. Winter, 25-40

41. Schoemaker PJH, van der Heijden CAJM (1992) Integrating Scenarios into Strategic Planning at Royal Dutch/Shell. Plan Rev 20(3):41-46

42. Shell International Limited (SIL) (2006) The Shell Global Scenarios to 2025

43. Singh M (2008) Future-focused supply chains - supply chain strategies shaped by the future. A research paper from the Center for Transportation \& Logistics, MIT.

44. Spolaore E, Wacziarg R (2005) Borders and growth. J Econ Growth 10(4):331-86

45. Supply Chain 2020 Project (2004) Proceedings of the Supply Chain 2020 Project's Industry Advisory Council Kickoff Meeting. MIT Faculty Club, May 24th, 2004

46. Supply Chain 2020 Project (2004) Supply Chain 2020 Project EAC Kickoff MIT Center for Transportation \& Logistics, Sept. 8th, 2004

47. Supply Chain 2020 Project. (2004) Proceedings of the Supply Chain 2020 Project's Industry Advisory Council. MIT Center for Transportation \& Logistics, Sept. 15th, 2004

48. Supply Chain 2020 Project. (2004) A Review of the Leading Opinions on the Future of Supply Chains. Supply Chain 2020 Project Working Paper, MIT Center for Transportation \& Logistics, December 6th, 2004

49. Tavasszy LA, Ruijgrok CJ, Thissen MJPM (2003) Emerging global logistics networks: implications for transport systems and policies. Growth Change 34(4):456-472

50. The Economist (2010) The next China. July 31st, August 6th, pp. $46-48$

51. The World Bank (2009) World Development Report 2009: Reshaping Economic Geography. Washington, DC

52. U.S. Bureau of the Census, International Programs Center, International Data Base (2006). US demographic trends

53. Venables A (2001) Geography and international inequalities: the impact of new technologies. J Ind Compet Trade 1(2):135-59

54. Venables A (2006) Shifts in economic geography and their causes. Econ Rev 2006 (Q IV), 61-85

55. Wack P (1985) Scenarios: Uncharted Waters Ahead. Harvard Business Review. September-October

56. Wolf M (2004) Why globalization work. Yale University Press 